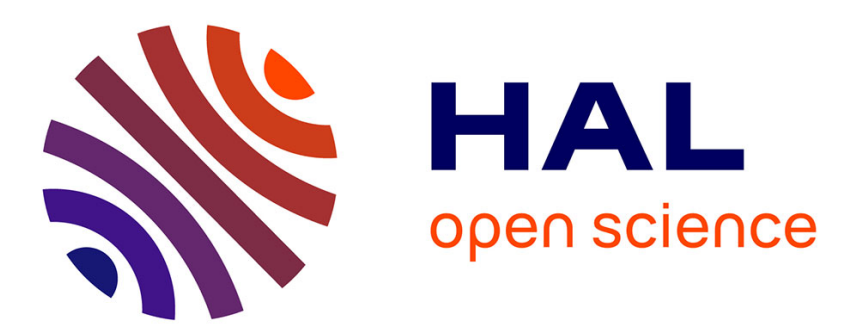

\title{
Electronic coupling in the reduced state lies at the origin of color changes of ommochromes
}

Florent Figon, Jérome Casas, Ilaria Ciofini, Carlo Adamo

\section{To cite this version:}

Florent Figon, Jérome Casas, Ilaria Ciofini, Carlo Adamo. Electronic coupling in the reduced state lies at the origin of color changes of ommochromes. Dyes and Pigments, 2021, 185, pp.108661. 10.1016/j.dyepig.2020.108661 . hal-02954670

\section{HAL Id: hal-02954670 https://hal.science/hal-02954670}

Submitted on 9 Nov 2020

HAL is a multi-disciplinary open access archive for the deposit and dissemination of scientific research documents, whether they are published or not. The documents may come from teaching and research institutions in France or abroad, or from public or private research centers.
L'archive ouverte pluridisciplinaire HAL, est destinée au dépôt et à la diffusion de documents scientifiques de niveau recherche, publiés ou non, émanant des établissements d'enseignement et de recherche français ou étrangers, des laboratoires publics ou privés. 


\title{
Electronic couplings in the reduced state lie at the origin of color changes of \\ ommochromes
}

\author{
Florent Figon $^{l *}$, Jérôme Casas ${ }^{1}$, Ilaria Ciofini ${ }^{2} *$ and Carlo Adamo ${ }^{2}$
}

${ }^{1}$ Institut de Recherche sur la Biologie de l'Insecte, UMR CNRS 7261, Université de Tours, 37200 Tours, France

${ }^{2}$ Chimie ParisTech, PSL University, CNRS, Institute of Chemistry for Life and Health Sciences, 75005 Paris, France

*Correspondence:

Florent Figon, Institut de Recherche sur la Biologie de l'Insecte, UMR CNRS 7261, Université de Tours, Faculté des Sciences et Techniques, Parc Grandmont, 37200 Tours, France; Email:

florent.figon@univ-tours.fr

Ilaria Ciofini, Chimie ParisTech, PSL University, CNRS, Institute of Chemistry for Life and Health Sciences, 11 rue Pierre et Marie Curie, 75005 Paris, France. Email: ilaria.ciofini@ chimie-paristech.fr

\section{Highlights}

1. Ommochrome pigments in insects uniquely display red shift upon reduction

2. Color changes were modelled at quantum level using TDDFT

3. Electron-withdrawing auxochromes affect optical properties only in reduced states

4. Electronic couplings that facilitate charge-transfer transitions drive red shifts

5. Larger red shifts are associated to higher antiradical behavior in reduced states

\section{Graphical Abstract}

Hypsochromy

Red.<smiles>CC(C)(C)c1c(O)cc2c(c1C#N)Nc1ccccc1O2</smiles>

Ox.<smiles>CC(C)(C)c1c2nc3ccccc3oc-2cc(=O)c1C(=O)OCc1ccccc1</smiles>

Bathochromy

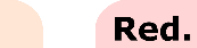




\begin{abstract}
In the colorful world of pigments and dyes, the chemical reduction of chromophores usually leads to bleaching because of $\pi$-conjugation interruption. Yet, the natural phenoxazinone-based ommochrome pigment called xanthommatin displays a bathochromic (i.e. red) shift upon twoelectron reduction to its corresponding phenoxazine, whose electronic origins are not completely disclosed. In this study, we investigated, at quantum chemical level, a series of phenoxazinone/phenoxazine pairs that was previously explored by UV-Vis spectroscopy (Schäfer and Geyer, 1972), and which displays different hypsochromic and bathochromic shifts upon reduction. Density Functional Theory (DFT) and Time-Dependent DFT (TDDFT) have been applied to compute their optical properties in order to find a rational explanation of the observed photophysical behavior. Based on our results, we propose that the electro-accepting power of auxochromes and their conjugation facilitate intramolecular charge-transfers across the phenoxazine bridge by lowering unoccupied molecular orbitals via electronic and geometric couplings, leading ultimately to bathochromy. Our findings therefore suggest new potential ways to adjust the color-changing ability of phenoxazinones in technological contexts. Overall, this model extends our mechanistic understanding of the many biological functions of ommochromes in invertebrates, from tunable color changes to antiradical behaviors.
\end{abstract}

Keywords: Antiradical, Bathochromy, Insect pigment, Ommochrome, Phenoxazine, TimeDependent Density Functional Theory 


\section{Introduction}

Chemical colors in animals are mostly produced by $\pi$-conjugated organic molecules, which contain a chromophore with alternating single and double bonds. Extending the electronic conjugation of chromophores usually leads to bathochromic shifts (i.e. absorption at longer wavelengths), while breaking the $\pi$-system induces hypsochromic shifts (i.e. absorption at shorter wavelengths) [1,2]. Therefore, even limited chemical reduction of organic dyes and pigments can result in their bleaching due to the saturation of double bonds [1]. However, one class of biological pigments -the phenoxazinone-based ommochromes- has appeared to be an exception to this rule [3]. Xanthommatin, the best-known and most-widespread ommochrome, is yellow in its oxidized state (oxo-pyrido[3,2-a]phenoxazinone; absorption at $440 \mathrm{~nm}$ ) but red when reduced to dihydroxanthommatin (oxo-pyrido[3,2-a]hydroxyphenoxazine; absorption at $480 \mathrm{~nm}$ ) [3]. This unusual color-changing molecular property mediates important biological functions [4], such as nuptial colorations in dragonflies [5], light filtering in insect eyes [6], as well as electron transfers in a marine worm [7,8] and various insects [9-11]. Besides, the bathochromic reduction of xanthommatin has shown biomimetic potential to craft colorchanging electrochromic devices [12]. Thus, unraveling the chemical origin of this distinct bathochromic reduction may have implications for both biologists and material scientists.

In 1972, Schäfer and Geyer synthesized a series of bathochromic and hypsochromic phenoxazinone/phenoxazine pairs to mimic ommochromes, and analyzed them by UV-Vis spectroscopy [13]. They showed that only 1-acetyl-2-[amino/hydroxy]-phenoxazin-3-ones (see Figure 1 for the numbering of phenoxazinones) underwent bathochromic reduction. They concluded that this bathochromic shift was due to an increased resonance in the molecular reduced states, in relation to the dipolar structure of the 1-acetyl auxochrome $[4,13]$. Unfortunately, after this pioneering experimental study, the model proposed was never further validated, nor rationalized making use of quantum chemical approaches. Yet, understanding the correlation between geometrical and electronic molecular structures with chromatic shifts in phenoxazinonic dyes and pigments hold great promises to further unravel their natural functions and technological uses.

The recent advances in quantum chemical methods for the description of ground and excited electronic states has greatly helped to rationalize and to predict the optical properties of molecules, especially in the case of organic dyes [14,15]. In particular, the advent of Density Functional Theory (DFT) and Time-Dependent DFT (TDDFT), together with an increased availability of computational resources, has enabled to successfully model a vast number of biochromes, pigments and dyes (see for instance references [16-18]). Because of its favorable 
cost-to-accuracy ratio, we selected TDDFT to investigate the properties of phenoxazinone/phenoxazine pairs firstly to test the validity of Schäfer and Geyer's model and then to rationalize the link between the structure and photophysical properties of ommochromes. However, since TDDFT performances may quantitatively depend on the exchange correlation functional used [15,19], a preliminary benchmark of commonly applied functionals has been performed on both phenoxazinones and phenoxazines. In particular, we tested a set of global hybrid functionals with various percentages of exact exchange, as well as range-separated hybrids (RSH), which usually perform better for excited states with a substantial amount of non-local charge transfer (CT). Once the computational approach set, several structural (e.g. planarity) and electronic properties (e.g. aromaticity indexes and CT character) were analyzed to establish the structure-property relationship of chromic shifts upon reduction. By applying the same techniques to ommochromes and resorufin, an important hypsochromic biotechnological dye, we rationalized their color-changing behavior upon reduction in terms of electronic and geometric couplings in the reduced phenoxazine state. Finally, our electronic model of ommochromes provides a mechanistic understanding of their unique optical properties, which helps rationalizing their widespread and various uses in invertebrates, as well as in new biomimetic applications.

\section{Computational Details}

\subsection{Computational Approaches and Benchmarks}

All quantum chemical calculations were performed with the Gaussian program [20] at the DFT level [21] while molecular orbitals were visualized using the Gabedit program [22].

The B3LYP functional [23] was used to locate minima since it generally provides reliable geometric parameters for organic compounds [24], while Grimme's dispersion correction using the D3(BJ) model $[25,26]$ was also introduced to account for weak interactions. Bulk solvent effects were considered using the COSMO approach to polarizable continuum models (CPCM) [27]. Different solvents were considered depending on experimental conditions $[4,13,28]$, as specified in Supporting Information (SI).

Each structural optimization was followed by a harmonic frequency calculation, ensuring that all computed vibrational frequencies were positive, as they should be for an energy minimum on the potential energy surface. The optimized coordinates of all investigated compounds investigated are listed in SI. The 6-311G(d,p) basis set was chosen for all structural optimizations, after a careful test (see SI for details). 
Using these molecular structures optimized at the identified theoretical level (B3LYPD3(BJ)/6-311G $(d, p)$, vertical absorption energies $\left(\Delta \mathrm{E}^{\mathrm{vert}}\right)$ were then computed within the linear response Time-Dependent DFT (TDDFT) framework [29] using the non-equilibrium approximation of CPCM [27]. It is well known that the computed electronic adsorption energies depend on the chosen DFT approach. While some general trends appear from previous detailed benchmarks $[19,30]$, it is a better practice to verify the performances on the systems under investigations. To this end, as functionals based on local-density (LDA) and generalized gradient approximation (GGA) are known to perform poorly for the calculation of vertical excited states [30], TDDFT calculations were carried out only considering 12 functionals, chosen among the most representative (see SI for details)

All 18 phenoxazinone/phenoxazine pairs depicted in Fig 1 were used for this TDDFT benchmark, while the experimental values were taken from reference [13]. If a compound in this dataset showed broad/unresolved absorbance peaks, the one with the highest wavelength was systematically used. The performance of the selected functionals was evaluated suing the following criteria: mean absolute errors (MAE) on $\Delta \mathrm{E}^{\mathrm{vert}}$ (target to be below $0.2 \mathrm{eV}$ ), comparable errors for both phenoxazinones $\left(\Delta \mathrm{E}^{\mathrm{vert}}{ }_{\mathrm{ox}}\right)$ and phenoxazines $\left(\Delta \mathrm{E}^{\mathrm{vert}}{ }_{\mathrm{red}}\right)$, MAE on chromic shifts (defined as $\Delta \mathrm{E}^{\mathrm{vert}}$ shift $=\Delta \mathrm{E}^{\mathrm{vert}}{ }_{\text {red }}-\Delta \mathrm{E}^{\mathrm{vert}}{ }_{\mathrm{ox}}$; target to be below $0.2 \mathrm{eV}$ ), comparable errors for both bathochromic and hypsochromic redox pairs, high correlations with experimental values for both absorption energies and chromic shifts, and high number of wellpredicted chromic shifts.

Based on this benchmark, whose results are reported and commented in the SI, the M05 functional [31] results as the best compromise and the most reliable functional for predicting the chromic reduction of phenoxazinones to phenoxazines.

Following previous experience [32] and the test carried out for the 2-amino-7-hydroxyphenoxazin-3-one molecule (see SI for details), all the vertical transition energies were computed using the $6-31+\mathrm{G}(\mathrm{d})$ basis set.

\subsection{Computation of Descriptors}

Several descriptors were considered in order to assess the relationship between the structural and electronic parameters of the considered dyes and their optical behavior.

The Harmonic oscillator model of aromaticity for heterocycle electron delocalization (HOMHED) is a geometric index of aromaticity that evaluates bond conjugation by comparing bond lengths of a compound to those of an ideal aromatic compound [33]. The closer to 1 
HOMHED is, the more conjugated, and thus aromatic, the compound is. The HOMED values were computed using the Gabedit program and the parameters described in reference [33].

Another commonly applied index is the so-called nucleus-independent chemical shifts (NICS) which is based on the deshielding induced at a center of an aromatic ring by the ring current [34]. The more deshielded NICS is, the more aromatic the compound. The NICS indexes were computed at the center of each ring (NICS(0)) using the above mentioned level of theory and the gauge-including atomic orbital (GIAO) method [35].

The third descriptor is the charge-transfer distance $\left(\mathrm{D}_{\mathrm{CT}}\right)$ that evaluates the hole-electron mean distance associated to an electronic excitation, thus unraveling its nature (local or charge transfer). It is easily computed measuring the distance between the barycenters of charge distributions corresponding to a density depletion and a density increase upon excitation [36].

Finally, some descriptors, issued from the so-called conceptual DFT [37], were also considered, including electron affinity (EA), hardness $(\eta)$ and electro-accepting power $\left(\omega^{+}\right)$. The latter measures the local charge-acceptance of a compound and thus its capacity to accept fractions of electron during charge-transfer phenomena [38,39].

\section{Results}

A total of 15 molecular pairs from Schäfer and Geyer's series [13] were considered for a detailed analysis (see SI for the explanation on this choice). Electronic and geometric properties of the bathochromic ommochrome pair xanthommatin/dihydroxanthommatin and the hypsochromic dye pair resorufin/dihydroresorufin were also investigated for sake of completeness. Experimental UV-Visible data for these molecules were taken from references [3] and [40], respectively.

\subsection{Schäfer and Geyer's Phenoxazine Series}

Nearly 50 years ago, Schäfer and Geyer proposed that the bathochromic shifts of some substituted phenoxazinones upon reduction could be related to an increase of resonance forms [13], and thus to a greater conjugation of the phenoxazine chromophore. To test this hypothesis, we computed two indices that can be related to the degree of delocalization and aromaticity in a molecule, namely the HOMHED and NICS(0) indexes [37].

The HOMHED index basically considers computed structural parameters, namely related to bond length alternation between single and double bonds, to evaluate the degree of electron delocalization, as detailed in the computational section. This index has been evaluated for two possible delocalization patterns in the molecule as highlighted in Figure 2A and Figure 
S7 namely: i) the pattern involving delocalization along ring C (cHOMHED, Fig 2A) and ii) the delocalization pattern along all bonds involved in the resonant forms produced by substituents in position 1, 2 and the phenoxazine nitrogen (sHOMHED, Fig S7). In contrast with the experimental hypothesis, no clear correlation with chromic shifts can be drawn in the case of the sHOMHED pathway Fig S7) while, in the case of the cHOMHED index, a partial positive correlation $\left(\mathrm{R}^{2}=0.77\right.$ ) can be found (Fig 2B). According to this index, hypsochromicity is associated with an increase in aromaticity of ring $\mathrm{C}$. This partial correlation is nonetheless lost when considering the $\operatorname{NICS}(0)$ index, an index based on electronic properties. While considering only bathochromic pairs (Fig 2C), a positive correlation between aromaticity and bathochromicity can be found $\left(\mathrm{R}^{2}\right.$ batho $\left.=0.79\right)$, in agreement with the experimental hypothesis, no correlation can be found if both batho and hypsochromic pairs are considered. Indeed three hypsochromic phenoxazines show the lowest NICS(0) and thus the highest aromaticity. In short, these two measures of the aromaticity, which are different in nature (electronic and structural origin), do not support the hypothesis of Schäfer and Geyer on the observed color change of ommochromes and, particularly on the different batho and hypsochromic behavior.

In order to have a general picture of these behaviors and to propose a more general rationalization of the chromic reduction of phenoxazinones to phenoxazines, we analyzed the general trends arising from the mean values and dispersion of the set of structural and electronic parameters chosen, as reported in Table 1.

First, we note a significant structural difference between phenoxazines and phenoxazinones, the first being sizably less planar that the latter $\left(+11.5^{\circ}\right.$; Table 1$)$, in agreement with the expected $\mathrm{sp}^{3}$ configuration of the phenoxazine nitrogen. Consistently, in average, both the cHOMHED and the NICS(0) indicate an increased aromaticity in the reduced systems (Table 1). Nonetheless, no correlation between chromicity and structural parameters can be directly established.

At the ground electronic state (GS), reduction leads to the destabilization of both the highest occupied molecular orbital $(\mathrm{HOMO},+1.47 \mathrm{eV})$ and the lowest unoccupied molecular orbital (LUMO, $+1.7 \mathrm{eV}$; Table 1). The HOMO-LUMO gap is only slightly higher in phenoxazines $(+0.23 \mathrm{eV})$ but the spreading of values for these systems is computed to be three times larger than for phenoxazinones (Table 1), thus indicating that phenoxazines present both significantly lower and higher HOMO-LUMO gaps than phenoxazinones. This pattern is mirrored by those of $\Delta \mathrm{E}^{\mathrm{vert}}$ and $\Delta \mathrm{E}^{\mathrm{exp}}$, consistently with the presence of batho and hypsochromic pairs. Looking at properties involving excited states, reduction leads to oscillator strengths and 
transition dipole moments more than twice lower than in phenoxazinones (Table 1). These data are in agreement with the hypochromic shift (i.e. less intense absorption) observed upon reduction to phenoxazines [13]. Finally, dipole moments and, consistently, the charge-transfer distances $\left(\mathrm{D}_{\mathrm{CT}}\right)$ associated to excited states are computed to be higher in phenoxazines $(+4.06$ D and $+0.9 \AA$, respectively; Table 1). This latter finding indicates a larger intramolecular charge transfer (ICT) character associated to electronic transitions in phenoxazines than in phenoxazinones.

More interestingly, we note that dispersion of the values associated to most of the electronic and structural parameters is greatly larger in phenoxazines (Table 1 and Fig 3A). Therefore, we can formulate the hypothesis that different chromic shifts are essentially driven by differences in the reduced systems independently of the corresponding oxidized ones. Consistently to this hypothesis, chromic shifts show a relatively strong linear correlation $\left(\mathrm{R}^{2}=\right.$ 0.84) with $\Delta \mathrm{E}^{\mathrm{vert}}$ red $\left(\right.$ Fig 3B) but no correlation at all with $\Delta \mathrm{E}^{\mathrm{vert}}{ }_{\text {ox }}$ (Fig S8). In line with these results, there is a clear distinction between $\Delta \mathrm{E}^{\mathrm{vert}}$ red of bathochromic and hypsochromic compounds, while $\Delta \mathrm{E}^{\mathrm{vert}}$ ox do no significantly differ (Fig 3A).

To further validate the hypothesis that chromicity is mainly linked to properties of the reduced forms, the electronic properties of four representative pairs, including two bathochromic (1 and 2) and two hypsochromic phenoxazines (14 and 15), were considered (Fig S9). In all cases, since the $\pi-\pi^{*}$ excited states of interest have a dominant HOMO-LUMO character for both oxidized and reduced compounds, energies of the HOMO and LUMO were firstly analyzed. Consistently with the results presented in Table 1, only the molecular orbital energies of the reduced compounds vary consistently with chromic shifts (Fig S10). Furthermore, the range of HOMO-LUMO gap values in phenoxazines is primarily associated to a wider variation in LUMO than in HOMO energies (Table 1 and Fig S10).

All these data suggest that a simple correlation could link chromic shifts to LUMO energies of reduced phenoxazines, which are in fine directly related to their electron affinity (EA) and thus to their reactivity and antiradical properties [41,42]. Indeed, a clear correlation is found between computed chromic shift and electron affinity of phenoxazines (EA red, Fig 4A; $\left.\mathrm{R}^{2}=0.61\right)$. This correlation is further improved by considering chemical hardness in the reduced states $\left(\eta_{\text {red }}\right.$, Fig $\left.4 B ; R^{2}=0.82\right)$, which implicitly takes into account also the variation of the energy of the HOMO level.

Since LUMOs energies can be tuned by the presence of electron-withdrawing auxochromic groups (EWA) [43], we computed the frontier orbital energies of the different 
EWA that can be placed in positions 1 and 8 (Fig 1). Consistently with our hypothesis, the two EWA (i.e. acetyl and $\gamma$-oxobutenyl) with the lowest LUMO energies and highest electroaccepting powers, $\omega^{+}$, are associated to bathochromic shifts, while EWA with high LUMO energies (such as cyano or carboxy substituted) induce hypsochromic shifts (Table 2). Of note, the tert.butyl-carbonyl EWA shows a hypsochromic shift whereas its LUMO energy is close to that of acetyl. This result indicates that other parameters than the LUMO stabilization may play a role in the observed shifts. In particular, tert.butyl-carbonyl is a bulky EWA compared to acetyl and carbomethoxy. In this case, as already proposed by Schäfer and Geyer, steric hindrance can altered excitation energies by constraining the carbonyl out-of-plane [13]. Such an effect is observed in the case of compound $\mathbf{1 4} \mathbf{r}$ for which a large dihedral angle between ring $\mathrm{C}$ and carbonyl in position 1 is computed $\left(59^{\circ}\right.$ in $\mathbf{1 4 r} v s 8^{\circ}$ in $1 \mathbf{r}$ ) (Fig S11). To test whether this torsion destabilized the LUMO and thereby induced the hypsochromic shift, we computed the $\Delta \mathrm{E}^{\mathrm{vert}}$ as a function of the torsional angle for compounds $1 \mathbf{r}, \mathbf{1 4 r}$ and $15 \mathbf{r}$ (Fig 5A). The results show that for dihedral angles greater than $30^{\circ}$ there is a significant hypsochromic effect, with the maximum hypsochromy obtained around $90^{\circ}$ (from $0.30 \mathrm{eV}$ for $1 \mathbf{r}$ to $0.83 \mathrm{eV}$ for $\mathbf{1 5 r}$; Fig 5A). Below $60^{\circ}, \mathbf{1 4 r}$ becomes less hypochromic than $15 \mathbf{r}$ in its optimized geometry (Fig $5 \mathrm{~A}$ ), in agreement with the lower LUMO energy of tert.butyl-carbonyl compared to carbomethoxy (Table 2). However, 14r can never reach the bathochromicity of $\mathbf{1 r}$, even at angles near $0^{\circ}$ (Fig 5A). These results indicate that the steric hindrance of tert.butyl-carbonyl explains, partly at least, the hypsochromicity of $\mathbf{1 4 r}$.

Next, we considered model systems obtained by functionalization of the 2-hydroxyphenoxazin-3-one/2,3-dimethoxy-phenoxazine pairs with EWA with either stabilized (nitro) or destabilized (carboxamide) LUMOs (Table S1 and Fig 5B-C). All substituents were placed in position 1 and forced to lie within ring $\mathrm{C}$ plane after geometrical optimization to avoid torsion of molecular orbitals due to steric hindrance. The results show that LUMO energies of substituents explain $95 \%$ of the variation in chromic shifts upon reduction (Fig 5B). They also confirme that increasing the electro-accepting power of substituents in position 1 leads to more bathochromic phenoxazines (Fig 5B-C and Table S1).

\subsection{Application to Ommochromes and Other Phenoxazinone Dyes}

Chromic shifts of two other important pairs of natural and technological relevance were next considered, namely xanthommatin/dihydroxanthommatin (bathochromic invertebrate pigments) and resorufin/dihydroresorufin (hypsochromic biotechnological dyes; see Figure 6 and Table S2). 
The 8-substituted-oxo-pyrido[3,2-a]phenoxazin-3-one xanthommatin presents HOMO $(-6.89 \mathrm{eV})$ and LUMO (-3.35 eV) energies very close to the mean HOMO and LUMO energies of the phenoxazinones investigated above (compare Fig 6 with Table 1 and Fig S9). The corresponding reduced 8-substituted-oxo-pyrido[3,2-a]-3-hydroxy-phenoxazine dihydroxanthommatin possesses not only a highly stabilized LUMO $(-2.02 \mathrm{eV})$, but also a relatively stabilized LUMO+1 $(-1.59 \mathrm{eV})$. Overall, the molecular orbitals of xanthommatin and dihydroxanthommatin resemble those of the phenoxazinones and phenoxazines described above both qualitatively and quantitatively (Fig 6 and Fig S9), which indicates that the effect of EWA on the reduced state should also control their chromic shifts. The substituent in position 8 if ommochromes is closely related to acetyl, while the oxo-pyrido ring attached on positions 1 and 2 resembles $\gamma$-oxo-butenyl. The two corresponding carbonyl functions lie within ring A and $\mathrm{C}$ planes, respectively. All these characteristics predicted a bathochromic shift upon reduction. Accordingly, the molecular orbital gaps of dihydroxanthommatin are $3.21 \mathrm{eV}$ (HOMO-LUMO) and $3.64 \mathrm{eV}$ (HOMO-L+1), thus they lie within, and even beyond, the range of bathochromic transitions already investigated in this study (Table 1). In addition, dihydroxanthommatin hardness is the lowest we computed (Table S2 and Table 1). Excited state computations consistently predict two bathochromically shifted electronic transitions, which involve a HOMO-LUMO and a HOMO-L+1 transitions, respectively (Table S2). Both transitions are characterized by a significant ICT (Table S1 and Fig 6). The first excited state (S1) is less intense than the second (S2) and their $\Delta \mathrm{E}^{\text {vert }}$ bracket the experimental value $\left(\Delta \mathrm{E}_{\mathrm{S} 1}{ }^{\text {vert }}\right.$ $=2.25 \mathrm{eV}<\Delta \mathrm{E}^{\exp }=2.58 \mathrm{eV}<\Delta \mathrm{E}_{\mathrm{S} 2}{ }^{\text {vert }}=2.69 \mathrm{eV}$ ), which corresponds to the maximum of a broad absorption peak [4].

On the contrary, the resorufin/dihydroresorufin pair presents all the characteristics associated to hypsochromic shifts: the absence of EWA, a small HOMO-LUMO gap in the oxidized state, a highly destabilized LUMO and high chemical hardness (Fig 6 and Table S2). Accordingly, TD-M05 calculations predict a highly hypsochromic shift upon reduction (1.05 $\mathrm{eV}$; Table S2). To the best of our knowledge, the exact experimental absorbance of dihydroresorufin has never been reported in the literature, but resorufin is known to lose its color upon reduction [28], which is in agreement with our calculations.

\section{Discussion}

The above reported results clearly show that the model originally proposed by Schäfer and Geyer to explain the experimentally observed chromic shifts in substituted phenoxazinone/phenoxazine pairs, which correlates bathochromic shifts to an increase in 
resonance structures [13], is unable to explain qualitatively why 1-acetyl-phenoxazines are bathochromic and why the closely-related 1-carbomethoxy-phenoxazines are hypsochromic. Our analysis, based on modern descriptors of aromaticity, invalidates the general applicability of this model, showing that there is no clear correlation between descriptors of aromaticity and bond conjugation with color changes upon reduction. On the other hand, it appears that bathochromic and hypsochromic shifts correlate well with electronic properties of reduced forms, in particular with all descriptors containing information on the strength and nature of the EWA present in the molecule, such as LUMO energy, electro-accepting power and EA.

On this basis, to explain the color-changing behavior of substituted phenoxazinones upon reduction, we propose the following structure-property model. (Fig 7). The bright excited state of phenoxazinones (i.e. oxidized forms) that is responsible for the yellow-orange color of this chromophore is of Locally Excited (LE) character stemming from a $\pi-\pi *$ transition. This transition is not particularity affected by EWA in position 1, explaining why excitation energies of substituted phenoxazinones do not vary significantly as a function of the EWA. Therefore, the energy of this LE state in phenoxazinones defines a common reference for bathochromy and hypsochromy of substituted phenoxazines (Fig 7B). The 3-hydroxy-phenoxazine chromophore (i.e the reduced form of the pair) is on the other hand characterized by a bright excited state displaying a partial intramolecular CT (ICT) character (Fig 7A). When 3-hydroxyphenoxazine is substituted in position 1 with a EWA, the EWA LUMO hybridizes with the phenoxazine UMOs and stabilizes them, thus lowering the energy of ICT. The strength of stabilization depends primarily on two factors (Fig 7A): (1) an electronic one that is the energy of EWA LUMO and (2) a structural one that is the magnitude of the dihedral angle formed by the EWA with the corresponding phenoxazine ring ruling its conjugation.

First, EWAs with high (low) electro-accepting powers stabilize (destabilize) the corresponding substituted phenoxazine UMOs, which decreases (increases) their excitation energies and leads to bathochromic (hypsochromic) shifts upon reduction (Fig 7B). This translates into ICT associated to lower (higher) energies, hence into red (yellow)-shifted colors (Fig 7B). This mechanism explains why acetyl and carbomethoxy induced bathochromic and hypsochromic shifts, respectively.

Second, from a structural viewpoint, when a substituent in position 1 is coplanar with the phenoxazine ring, the (L)UMOs are fully conjugated and thus highly stabilized. Structural decoupling decreases this effect (Fig 7B) explaining why sterically hindered EWA, despite having a high electro-accepting power can indeed induce hypsochromic shifts, as in the case of the tert.butyl-carbonyl. The same applies for the methylated phenoxazine nitrogen that induced 
a hypsochromic shift because of steric hindrance with the acetyl in position 1 , as already proposed by Schäfer and Geyer [13]. Overall, we propose that electronic and geometric interactions of EWA with the phenoxazine UMOs produce a wide range of ICT energies, which ultimately leads to a continuous hypso-to-bathochromic scale (Fig 7B).

Note that this model can be refined in several ways. For example, we could take into account the effect of electron-donating auxochromes (EDA) on the phenoxazine HOMO. This would explain why HOMO-LUMO gaps, rather than LUMO alone, better predicted chromic shifts in the complete set of investigated compounds (in which EDA in position 2 varies). We could also add the effect of EWA in other positions than 1. From the investigated compounds, it appears that EWA at position 5, 6, 7 and 8 have an effect on the phenoxazinone LUMO too, which (slightly) modifies the threshold for bathochromy. Most interestingly, EWA in position 8 could interact with the EWA in position 1 either synergistically (both EWA are similar and stabilize the same ICT, see 8r), additively (different bathochromic EWA stabilize two different ICT, see dihydroxanthommatin) or antagonistically (hypsochromic and bathochromic EWA lead to ICT not stabilized enough, see 9r). Note that for pair 9 TD-M05 calculations could not predict the correct color-changing behavior upon reduction. This indicates that other parameters not modelled in this study, such as direct solvent interactions [16], could also finely tune the color-changing effect of reduction.

Of note, the structure-to-property relation found here has also implication for the reactivity of these compounds. Indeed, HOMO-LUMO gap and LUMO energy are known to be directly related to hardness and electron affinity, respectively, which define some aspects of the chemical reactivity of a compound [39]. Our calculations showed that those two chemical parameters were highly correlated with the direction of chromic shift. We conclude that the softer and the more electrophilic a phenoxazine is, the more bathochromic and antiradical it becomes.

\section{Conclusions}

In this study, we unraveled the electronic mechanisms behind the atypical bathochromic (i.e. red shift) reduction of ommochrome pigments in invertebrates, particularly at play in the ecologically important nuptial coloration of dragonflies [5]. We established the relation between the nature and strength of electron-withdrawing auxochromes (EWA) that rules the magnitude of the phenoxazine intramolecular charge-transfer and the observed chromic shift. Other parameters, such as the angle formed by EWA with the attached phenoxazine ring, tune the direction of the chromic shift upon reduction. 
From a technological viewpoint, crafting phenoxazines with new EWAs that allow a wider range of chromic shifts than currently available [12] might foster the field of ommochrome-based electro-chromic devices. The influence of EWA conjugation on chromic shifts suggests that these devices could be made even more flexible by dynamically altering the torsion angle of EWAs, for example through tunable interactions with the coated surface.

From a biological viewpoint, it is well established that optical properties and chemical behaviors are both important functions of pigments [1,44-46]. By linking together those two functions through EWA properties, our study suggests that invertebrates may have favored bathochromic ommochromes because of both their better capacity to protect cells against reactive species in the reduced state, as previously suggested [42], and their tunable red shift, which we discuss in two biological situations. First, the occurrence of a decarboxylated form of xanthommatin can be explained by its decarboxylated EWA producing a less bathochromic reduced state. It could therefore allow a wider range of colorations than with xanthommatin alone, as seen in cephalopods [47]. Second, it has long been known that absorbance spectra of ommochromes are red-shifted in insects eyes compared to in vitro $([6,48,49])$. We propose that properties of the matrix in which ommochromes are deposited and that alter their absorbance, such as proteins [49,50] and metals [51,52], do so by modulating the electrophilicity and the conjugation of ommochrome EWAs, leading ultimately to their bathochromic behaviors uniquely observed in vivo.

In conclusion, our study reinforces the idea that the unique electronic properties of ommochromes make them a powerful technological and biological framework to tune rapidly and efficiently color-changing materials.

\section{Acknowledgments}

We are grateful to Alistar Ottochian, Michele Turelli and Bernardino Tirri for their technical support. F.F. thanks the ENS de Lyon for financial support. I.C. gratefully acknowledges support from the European Research Council (ERC) for funding under the European Union's Horizon 2020 research and innovation program (grant agreement No 648558, STRIGES CoG grant). This works formed part of the doctoral dissertation of F.F. under the supervision of J.C. 


\section{References}

[1] Needham AE. The significance of zoochromes. vol. 3. Berlin, Heidelberg, New York: SpringerVerlag; 1974.

[2] Nassau K. The fifteen causes of color: The physics and chemistry of color. Color Res Appl 1987;12:4-26. https://doi.org/10.1002/col.5080120105.

[3] Figon F, Casas J. Ommochromes in invertebrates: biochemistry and cell biology. Biological Reviews 2019;94:156-83. https://doi.org/10.1111/brv.12441.

[4] Linzen B. The Tryptophan $\rightarrow$ Ommochrome Pathway in Insects. In: Treherne JE, Berridge MJ, Wigglesworth VB, editors. Advances in Insect Physiology, vol. 10, Academic Press: Elsevier; 1974, p. 117-246.

[5] Futahashi R, Kurita R, Mano H, Fukatsu T. Redox alters yellow dragonflies into red. Proceedings of the National Academy of Sciences 2012;109:12626-31. https://doi.org/10.1073/pnas.1207114109.

[6] Langer H. Properties and functions of screening pigments in insect eyes. Photoreceptor optics, Berlin, Heidelberg: Springer; 1975, p. 429-455.

[7] Horowitz NH, Baumberger JP. Studies on the respiratory pigment of Urechis eggs. Journal of Biological Chemistry 1941;141:407-15.

[8] Linzen B. Über Ommochrome, XV. Über die Identifizierung des „Urechochroms“ als Xanthommatin. Hoppe-Seyler's Zeitschrift Für Physiologische Chemie 1959;314:12-4. https://doi.org/10.1515/bchm2.1959.314.1.12.

[9] Linzen B, Bückmann D. Biochemische und histologische Untersuchungen zur Umfärbung der Raupe von Cerura vinula L. Zeitschrift für Naturforschung B 1961;16:6-18. https://doi.org/10.1515/znb-1961-0104.

[10] Harano T, Chino H. A new diaphorase from Bombyx silkworm eggs-Cytochrome c reductase activity mediated with xanthommatin. Archives of Biochemistry and Biophysics 1971;146:46776. https://doi.org/10.1016/0003-9861(71)90150-0.

[11] Bellamy D. The structure and metabolic properties of tissue preparations from Schistocerca gregaria (desert locust). Biochemical Journal 1958;70:580-9. https://doi.org/10.1042/bj0700580.

[12] Kumar A, Williams TL, Martin CA, Figueroa-Navedo AM, Deravi LF. Xanthommatin-Based Electrochromic Displays Inspired by Nature. ACS Applied Materials \& Interfaces 2018. https://doi.org/10.1021/acsami.8b14123.

[13] Schäfer W, Geyer I. Über das redoxverhalten der ommochrome UV/S-spektren von 3hphenoxazinonen-(3) und phenoxazinen. Tetrahedron 1972;28:5261-79. https://doi.org/10.1016/S0040-4020(01)88945-6.

[14] Jacquemin D, Perpète EA, Ciofini I, Adamo C. Accurate Simulation of Optical Properties in Dyes. Acc Chem Res 2009;42:326-34. https://doi.org/10.1021/ar800163d. 
[15] Di Tommaso S, Bousquet D, Moulin D, Baltenneck F, Riva P, David H, et al. Theoretical approaches for predicting the color of rigid dyes in solution. J Comput Chem 2017;38:998-1004. https://doi.org/10.1002/jcc.24774.

[16] Adamo C, Barone V. A TDDFT study of the electronic spectrum of s-tetrazine in the gas-phase and in aqueous solution. Chemical Physics Letters 2000;330:152-60. https://doi.org/10.1016/S0009-2614(00)01082-4.

[17] Barone V, Biczysko M, Borkowska-Panek M, Bloino J. A Multifrequency Virtual Spectrometer for Complex Bio-Organic Systems: Vibronic and Environmental Effects on the UV/Vis Spectrum of Chlorophyll $a$. ChemPhysChem 2014;15:3355-64. https://doi.org/10.1002/cphc.201402300.

[18] Ferré N, Filatov M, Huix-Rotllant M, editors. Density-functional methods for excited states. Cham: Springer; 2016.

[19] Laurent AD, Jacquemin D. TD-DFT benchmarks: A review. Int J Quantum Chem 2013;113:201939. https://doi.org/10.1002/qua.24438.

[20] Frisch MJ, Trucks GW, Schlegel HB, Scuseria GE, Robb MA, Cheeseman JR, et al. Gaussian 16 Rev. C.01. Wallingford, CT: 2016.

[21] Kohn W, Becke AD, Parr RG. Density functional theory of electronic structure. The Journal of Physical Chemistry 1996;100:12974-12980.

[22] Allouche A-R. Gabedit-A graphical user interface for computational chemistry softwares. J Comput Chem 2011;32:174-82. https://doi.org/10.1002/jcc.21600.

[23] Becke A. Density-functional thermochemistry. III. The role of exact exchange. The Journal of Chemical Physics 1993;98:5648.

[24] Jacquemin D, Preat J, Perpète EA, Vercauteren DP, André J-M, Ciofini I, et al. Absorption spectra of azobenzenes simulated with time-dependent density functional theory. Int J Quantum Chem 2011;111:4224-40. https://doi.org/10.1002/qua.22910.

[25] Grimme S, Ehrlich S, Goerigk L. Effect of the damping function in dispersion corrected density functional theory. J Comput Chem 2011;32:1456-65. https://doi.org/10.1002/jcc.21759.

[26] Becke AD, Johnson ER. Exchange-hole dipole moment and the dispersion interaction revisited. The Journal of Chemical Physics 2007;127:154108. https://doi.org/10.1063/1.2795701.

[27] Cossi M, Rega N, Scalmani G, Barone V. Energies, structures, and electronic properties of molecules in solution with the C-PCM solvation model. J Comput Chem 2003;24:669-81. https://doi.org/10.1002/jcc.10189.

[28] Song P, Ruan M, Sun X, Zhang Y, Xu W. Theoretical Study of Resorufin Reduction Mechanism by NaBH 4. J Phys Chem B 2014;118:10224-31. https://doi.org/10.1021/jp505739p.

[29] Casida ME. Time-dependent density-functional theory for molecules and molecular solids. Journal of Molecular $\quad$ Structure: $\quad$ THEOCHEM 2009;914:3-18. https://doi.org/10.1016/j.theochem.2009.08.018. 
[30] Jacquemin D, Wathelet V, Perpète EA, Adamo C. Extensive TD-DFT Benchmark: Singlet-Excited States of Organic Molecules. J Chem Theory Comput 2009;5:2420-35. https://doi.org/10.1021/ct900298e.

[31] Zhao Y, Schultz NE, Truhlar DG. Exchange-correlation functional with broad accuracy for metallic and nonmetallic compounds, kinetics, and noncovalent interactions. The Journal of Chemical Physics 2005;123:161103. https://doi.org/10.1063/1.2126975.

[32] Ciofini I, Adamo C. Accurate Evaluation of Valence and Low-Lying Rydberg States with Standard Time-Dependent Density Functional Theory. J Phys Chem A 2007;111:5549-56. https://doi.org/10.1021/jp0722152.

[33] Frizzo CP, Martins MAP. Aromaticity in heterocycles: new HOMA index parametrization. Struct Chem 2012;23:375-80. https://doi.org/10.1007/s11224-011-9883-z.

[34] Chen Z, Wannere CS, Corminboeuf C, Puchta R. Nucleus-Independent Chemical Shifts (NICS) as an Aromaticity Criterion. Chemical Reviews 2005;105:3842-88. https://doi.org/10.1021/cr030088+.

[35] Cheeseman JR, Trucks GW, Keith TA, Frisch MJ. A comparison of models for calculating nuclear magnetic resonance shielding tensors. The Journal of Chemical Physics 1996;104:5497-509. https://doi.org/10.1063/1.471789.

[36] Le Bahers T, Adamo C, Ciofini I. A Qualitative Index of Spatial Extent in Charge-Transfer Excitations. J Chem Theory Comput 2011;7:2498-506. https://doi.org/10.1021/ct200308m.

[37] De Proft F, Geerlings P. Conceptual and Computational DFT in the Study of Aromaticity. Chem Rev 2001;101:1451-64. https://doi.org/10.1021/cr9903205.

[38] Gázquez JL, Cedillo A, Vela A. Electrodonating and Electroaccepting Powers. J Phys Chem A 2007;111:1966-70. https://doi.org/10.1021/jp065459f.

[39] Pearson RG. The electronic chemical potential and chemical hardness. Journal of Molecular Structure: THEOCHEM 1992;255:261-70. https://doi.org/10.1016/0166-1280(92)85014-C.

[40] Kitson TM. The Oxidative Addition Reaction between Compounds of Resorufin (7-Hydroxy-3Hphenoxazin-3-one) and 2-Mercaptoethanol. Bioorganic Chemistry 1998;26:63-73. https://doi.org/10.1006/bioo.1998.1079.

[41] Martínez A, Rodríguez-Gironés MA, Barbosa A, Costas M. Donator Acceptor Map for Carotenoids, Melatonin and Vitamins. The Journal of Physical Chemistry A 2008;112:9037-42. https://doi.org/10.1021/jp803218e.

[42] Romero Y, Martínez A. Antiradical capacity of ommochromes. Journal of Molecular Modeling 2015;21. https://doi.org/10.1007/s00894-015-2773-3.

[43] Mao Y, Head-Gordon M, Shao Y. Unraveling substituent effects on frontier orbitals of conjugated molecules using an absolutely localized molecular orbital based analysis. Chem Sci 2018;9:8598607. https://doi.org/10.1039/C8SC02990C. 
[44] McGraw KJ. The antioxidant function of many animal pigments: are there consistent health benefits of sexually selected colourants? Animal Behaviour 2005;69:757-64. https://doi.org/10.1016/j.anbehav.2004.06.022.

[45] Gandía-Herrero F, Escribano J, García-Carmona F. Biological Activities of Plant Pigments Betalains. Critical Reviews in Food Science and Nutrition 2016;56:937-45. https://doi.org/10.1080/10408398.2012.740103.

[46] Ostrovsky MA, Dontsov AE. Vertebrate Eye Melanosomes and Invertebrate Eye Ommochromes as Antioxidant Cell Organelles: Part 2. Biol Bull Russ Acad Sci 2019;46:105-16. https://doi.org/10.1134/S1062359019010084.

[47] Williams TL, DiBona CW, Dinneen SR, Jones Labadie SF, Chu F, Deravi LF. Contributions of Phenoxazone-Based Pigments to the Structure and Function of Nanostructured Granules in Squid Chromatophores. Langmuir 2016;32:3754-9. https://doi.org/10.1021/acs.langmuir.6b00243.

[48] Höglund G, Langer H, Struwe G, Thorell B. Spectral absorption by screening pigment granules in the compound eyes of a moth and a wasp. Zeitschrift Für Vergleichende Physiologie 1970;67:238242.

[49] Langer H. Über die Pigmentgranula im Facettenauge von Calliphora erythrocephala. Zeitschrift für vergleichende Physiologie 1967;55:354-77. https://doi.org/10.1007/BF00302622.

[50] Williams TL, Senft SL, Yeo J, Martín-Martínez FJ, Kuzirian AM, Martin CA, et al. Dynamic pigmentary and structural coloration within cephalopod chromatophore organs. Nature Communications 2019;10. https://doi.org/10.1038/s41467-019-08891-x.

[51] Liao J-H, Chen C-S, Hu C-C, Chen W-T, Wang S-P, Lin I-L, et al. Ditopic Complexation of Selenite Anions or Calcium Cations by Pirenoxine: An Implication for Anti-Cataractogenesis. Inorganic Chemistry 2011;50:365-77. https://doi.org/10.1021/ic102151p.

[52] White RH, Michaud NA. Calcium is a component of ommochrome pigment granules in insect eyes. Comparative Biochemistry and Physiology Part A: Physiology 1980;65:239-42. https://doi.org/10.1016/0300-9629(80)90232-7. 


\section{Tables}

Table 1. Average values and dispersion of electronic and structural parameters computed for oxidized phenoxazinones and reduced phenoxazines.

\begin{tabular}{|c|c|c|}
\hline & $\begin{array}{l}\text { Phenoxazinone } \\
(\text { mean } \pm \text { SD })\end{array}$ & $\begin{array}{l}\text { Phenoxazine } \\
(\text { mean } \pm \text { SD })\end{array}$ \\
\hline$\Delta \mathrm{E}^{\exp }(\mathrm{eV})^{\mathrm{a}}$ & $\begin{array}{c}2,80 \\
\pm 0,10\end{array}$ & $\begin{array}{c}2,91 \\
\pm 0,20\end{array}$ \\
\hline$\Delta \mathrm{E}^{\mathrm{vert}}(\mathrm{eV})$ & $\begin{array}{c}2,71 \\
\pm 0,09\end{array}$ & $\begin{array}{c}2,75 \\
\pm 0,23\end{array}$ \\
\hline $\begin{array}{c}\text { Phenoxazinone/Phenoxazine } \\
\text { dihedral angle }\left(^{\circ}\right)\end{array}$ & $\begin{array}{c}0,6 \\
\pm 0,3\end{array}$ & $\begin{array}{r}12,0 \\
\pm 5,9\end{array}$ \\
\hline $\begin{array}{l}\text { HOMO energy } \\
\qquad(\mathrm{eV})\end{array}$ & $\begin{array}{l}-6,84 \\
\pm 0,14\end{array}$ & $\begin{array}{l}-5,37 \\
\pm 0,10\end{array}$ \\
\hline $\begin{array}{l}\text { LUMO energy } \\
(\mathrm{eV})\end{array}$ & $\begin{array}{l}-3,34 \\
\pm 0,13\end{array}$ & $\begin{array}{l}-1,64 \\
\pm 0,25\end{array}$ \\
\hline $\begin{array}{l}\text { HOMO-LUMO } \\
\text { gap }(\mathrm{eV})\end{array}$ & $\begin{array}{c}3,50 \\
\pm 0,08\end{array}$ & $\begin{array}{c}3,73 \\
\pm 0,26\end{array}$ \\
\hline $\begin{array}{l}\text { Oscillator } \\
\text { strength }\end{array}$ & $\begin{array}{c}0,83 \\
\pm 0,21\end{array}$ & $\begin{array}{c}0,40 \\
\pm 0,15\end{array}$ \\
\hline $\begin{array}{l}\text { Transition dipole } \\
\text { moment (D) }\end{array}$ & $\begin{array}{r}12,45 \\
\pm 3,41\end{array}$ & $\begin{array}{c}5,85 \\
\pm 2,58\end{array}$ \\
\hline $\begin{array}{l}\text { Dipole moment } \\
\text { of GS (D) }\end{array}$ & $\begin{array}{c}6,34 \\
\pm 1,98\end{array}$ & $\begin{array}{c}6,52 \\
\pm 2,56\end{array}$ \\
\hline $\begin{array}{l}\text { Dipole moment } \\
\text { of ES (D) }\end{array}$ & $\begin{array}{c}8,29 \\
\pm 2,70\end{array}$ & $\begin{array}{r}12,35 \\
\pm 4,19\end{array}$ \\
\hline $\begin{array}{l}\text { NICS }(0) \text { of ring } \mathrm{C} \\
\quad(\mathrm{ppm})\end{array}$ & $\begin{array}{l}-0,87 \\
\pm 0,64\end{array}$ & $\begin{array}{l}-8,77 \\
\pm 0,54\end{array}$ \\
\hline cHOMHED of ring $\mathrm{C}$ & $\begin{array}{c}0,65 \\
\pm 0,05\end{array}$ & $\begin{array}{c}0,97 \\
\pm 0,01\end{array}$ \\
\hline $\mathrm{D}_{\mathrm{CT}}(\AA)$ & $\begin{array}{c}1,71 \\
\pm 0,30\end{array}$ & $\begin{array}{c}2,61 \\
\pm 0,60\end{array}$ \\
\hline
\end{tabular}

${ }^{\mathrm{a}}$ Experimental values are taken from reference [13] 
Table 2. Computed chemical descriptors (in eV) of electron-withdrawing auxochromes (EWA) in relation with the chromic shifts they induce experimentally in phenoxazinone/phenoxazine pairs.

\begin{tabular}{ccccc}
\hline EWA & HOMO & LUMO & H-L gap & $\omega^{+}$ \\
\hline Acetyl & -7.64 & -0.59 & 7.06 & 1.01 \\
$\gamma$ bathochromic shifts & 2.05 \\
Carbo-butenyl & -7.56 & -1.59 & 5.97 & \\
& hypsochromic shifts & & 0.72 \\
Cyano & -8.59 & 0.01 & 8.60 & 0.74 \\
tert.butyl-carbonyl & -10.61 & 0.32 & 10.93 & 0.98 \\
\hline
\end{tabular}




\section{Figure captions}

Figure 1. Set of substituted phenoxazin-3-ones and 3-methoxy-phenoxazines investigated in this study.

Figure 2. Computed vertical chromic shifts ( $\Delta \mathrm{E}^{\mathrm{vert}}$ shift) of phenoxazinone/phenoxazine pairs as a function of two aromaticity indexes (A), cHOMHED (B) and NICS(0) (C), of phenoxazines. Batho, bathochromy. Hypso, hypsochromy. Red, reduced state (i.e. phenoxazine).

Figure 3. Relationship between computed vertical excitation energies $\left(\Delta \mathrm{E}^{\mathrm{vert}}\right)$ chromic shifts of phenoxazinone/phenoxazine pairs. Batho, bathochromy. Hypso, hypsochromy. Red, reduced state (i.e. phenoxazine).

Figure 4. Comparison of chromic shifts ( $\Delta \mathrm{E}^{\mathrm{vert}}$ shift) of phenoxazinone/phenoxazine pairs with electron affinity (EA, A) and chemical hardness $(\eta, B)$ of phenoxazines. Batho, bathochromy. Hypso, hypsochromy. Red, reduced state (i.e. phenoxazine).

Figure 5. Comparison of computed chromic shifts $\left(\Delta \mathrm{E}^{\mathrm{vert}}\right.$ shift $)$ of phenoxazinone/phenoxazine pairs with geometric (A) and electronic (B-C) properties of electron-withdrawing auxochromes (EWA) in position 1. Batho, bathochromy. Hypso, hypsochromy. Arrow, angle at the optimized geometry.

Figure 6. Orbital diagrams of the bathochromic ommochrome pair xanthommatin/dihydroxanthommatin and the hypsochromic pair resorufin/dihydroresorufin. ICTs, intramolecular charge-transfers; LE, local excitation.

Figure 7. Model of the effect of geometric and electronic couplings on chromic shifts and chemical behaviors of phenoxazinone/phenoxazine pairs upon reduction. EWA, electronwithdrawing auxochrome. EDA, electron-donating auxochrome. ICT, intramolecular charge-transfer. $\mathrm{e}^{-(*)}$, (excited) electron. 


\section{Figures}

\section{Oxidized form}

(phenoxazin-3-one)<smiles>[R8]c1c2nc3c([R2])c([R2])c([R6])c([R6])c3oc-2cc(=O)c1[R7]</smiles>

\section{$\stackrel{\text { Reduction }}{\longrightarrow}$}

(6o) $\mathrm{R} 1=\mathrm{R} 8=\mathrm{COCH}_{3} ; \mathrm{R} 2=\mathrm{Cl}$

(7o) $\mathrm{R} 1=\mathrm{COCH}_{3} ; \mathrm{R} 2=\mathrm{OH} ; \mathrm{R} 8=\mathrm{C}_{2} \mathrm{H}_{2}-\mathrm{COCH}_{3}$

(8o) $\mathrm{R} 1=\mathrm{COCH}_{3} ; \mathrm{R} 2=\mathrm{OH} ; \mathrm{R} 6=\mathrm{C}_{2} \mathrm{H}_{2}-\mathrm{COCH}_{3}$

(9o) $\mathrm{R} 1=\mathrm{COCH}_{3} ; \mathrm{R} 2=\mathrm{OH} ; \mathrm{R} 8=\mathrm{COOCH}_{3}$

(10o) $\mathrm{R} 1=\mathrm{R} 6=\mathrm{COCH}_{3} ; \mathrm{R} 2=\mathrm{NH}_{2}$

(110) $\mathrm{R} 1=\mathrm{R} 8=\mathrm{COCH}_{3} ; \mathrm{R} 2=\mathrm{NH}-\mathrm{C}_{6} \mathrm{H}_{5}$

(12o) $\mathrm{R} 1=\mathrm{R} 8=\mathrm{COCH}_{3} ; \mathrm{R} 2=\mathrm{NH}-\mathrm{C}_{6} \mathrm{H}_{4}-\mathrm{pOCH}_{3}$

(13o) $\mathrm{R} 1=\mathrm{CN} ; \mathrm{R} 2=\mathrm{OH}$

(14o) $\mathrm{R} 1=\mathrm{CO}-\mathrm{C}\left(\mathrm{CH}_{3}\right)_{3} ; \mathrm{R} 2=\mathrm{OH}$

(15o) $\mathrm{R} 1=\mathrm{COOCH}_{3} ; \mathrm{R} 2=\mathrm{OH}$

(16o) $\mathrm{R} 1=\mathrm{COOCH}_{3} ; \mathrm{R} 2=\mathrm{OH} ; \mathrm{R} 7=\mathrm{CH}_{3}$

(170) R1 $=\mathrm{COOCH}_{3} ; \mathrm{R} 2=\mathrm{OH} ; \mathrm{R} 6=\mathrm{COCH}_{3}$

(180) $\mathrm{R} 1=\mathrm{COOCH}_{3} ; \mathrm{R} 2=\mathrm{OH} ; \mathrm{R} 5=\mathrm{COCH}_{3}$
Reduced form

(3-methoxy-phenoxazine)<smiles>[R2]c1c(OC)cc2c(c1[R1])N([R6])c1c([R8])c([R6])c([R2])c([R6])c1O2</smiles>

(1r) $\mathrm{R} 1=\mathrm{COCH}_{3} ; \mathrm{R} 2=\mathrm{OCH}_{3}$

(2r) $\mathrm{R} 1=\mathrm{R} 8=\mathrm{COCH}_{3} ; \mathrm{R} 2=\mathrm{OCH}_{3}$

(3r) $\mathrm{R} 1=\mathrm{R} 8=\mathrm{COCH}_{3} ; \mathrm{R} 2=\mathrm{NH}_{2}$

(4r) R1 = R8 $=\mathrm{COCH}_{3} ; \mathrm{R} 2=\mathrm{NHCH}_{3}$

(5r) $\mathrm{R} 1=\mathrm{R} 8=\mathrm{COCH}_{3} ; \mathrm{R} 2=\mathrm{N}\left(\mathrm{CH}_{3}\right)_{2}$

(6r) $\mathrm{R} 1=\mathrm{R} 8=\mathrm{COCH}_{3} ; \mathrm{R} 2=\mathrm{Cl}$

(7r) $\mathrm{R} 1=\mathrm{COCH}_{3} ; \mathrm{R} 2=\mathrm{OCH}_{3} ; \mathrm{R} 8=\mathrm{C}_{2} \mathrm{H}_{2}-\mathrm{COCH}_{3}$

(8r) $\mathrm{R} 1=\mathrm{COCH}_{3} ; \mathrm{R} 2=\mathrm{OCH}_{3} ; \mathrm{R} 6=\mathrm{C}_{2} \mathrm{H}_{2}-\mathrm{COCH}_{3}$

(9r) R1 $=\mathrm{COCH}_{3} ; \mathrm{R} 2=\mathrm{OCH}_{3} ; \mathrm{R} 8=\mathrm{COOCH}_{3}$

(10r) $\mathrm{R} 1=\mathrm{R} 6=\mathrm{COCH}_{3} ; \mathrm{R} 2=\mathrm{N}\left(\mathrm{CH}_{3}\right)_{2} ; \mathrm{R} 10=\mathrm{CH}_{3}$

(11r) $\mathrm{R} 1=\mathrm{R} 8=\mathrm{COCH}_{3} ; \mathrm{R} 2=\mathrm{NH}-\mathrm{C}_{6} \mathrm{H}_{5}$

(12r) $\mathrm{R} 1=\mathrm{R} 8=\mathrm{COCH}_{3} ; \mathrm{R} 2=\mathrm{NH}-\mathrm{C}_{6} \mathrm{H}_{4}-\mathrm{pOCH}_{3}$

(13r) $\mathrm{R} 1=\mathrm{CN} ; \mathrm{R} 2=\mathrm{OCH}_{3}$

(14r) R1 = $\mathrm{CO}-\mathrm{C}\left(\mathrm{CH}_{3}\right)_{3} ; \mathrm{R} 2=\mathrm{OCH}_{3}$

(15r) R1 $=\mathrm{COOCH}_{3} ; \mathrm{R} 2=\mathrm{OCH}_{3}$

(16r) $\mathrm{R} 1=\mathrm{COOCH}_{3} ; \mathrm{R} 2=\mathrm{OCH}_{3} ; \mathrm{R} 7=\mathrm{CH}_{3}$

(17r) R1 $=\mathrm{COOCH}_{3} ; \mathrm{R} 2=\mathrm{OCH}_{3} ; \mathrm{R} 6=\mathrm{COCH}_{3}$

(18r) R1 $=\mathrm{COOCH}_{3} ; \mathrm{R} 2=\mathrm{OCH}_{3} ; \mathrm{R} 5=\mathrm{COCH}_{3}$

Figure 1 
A
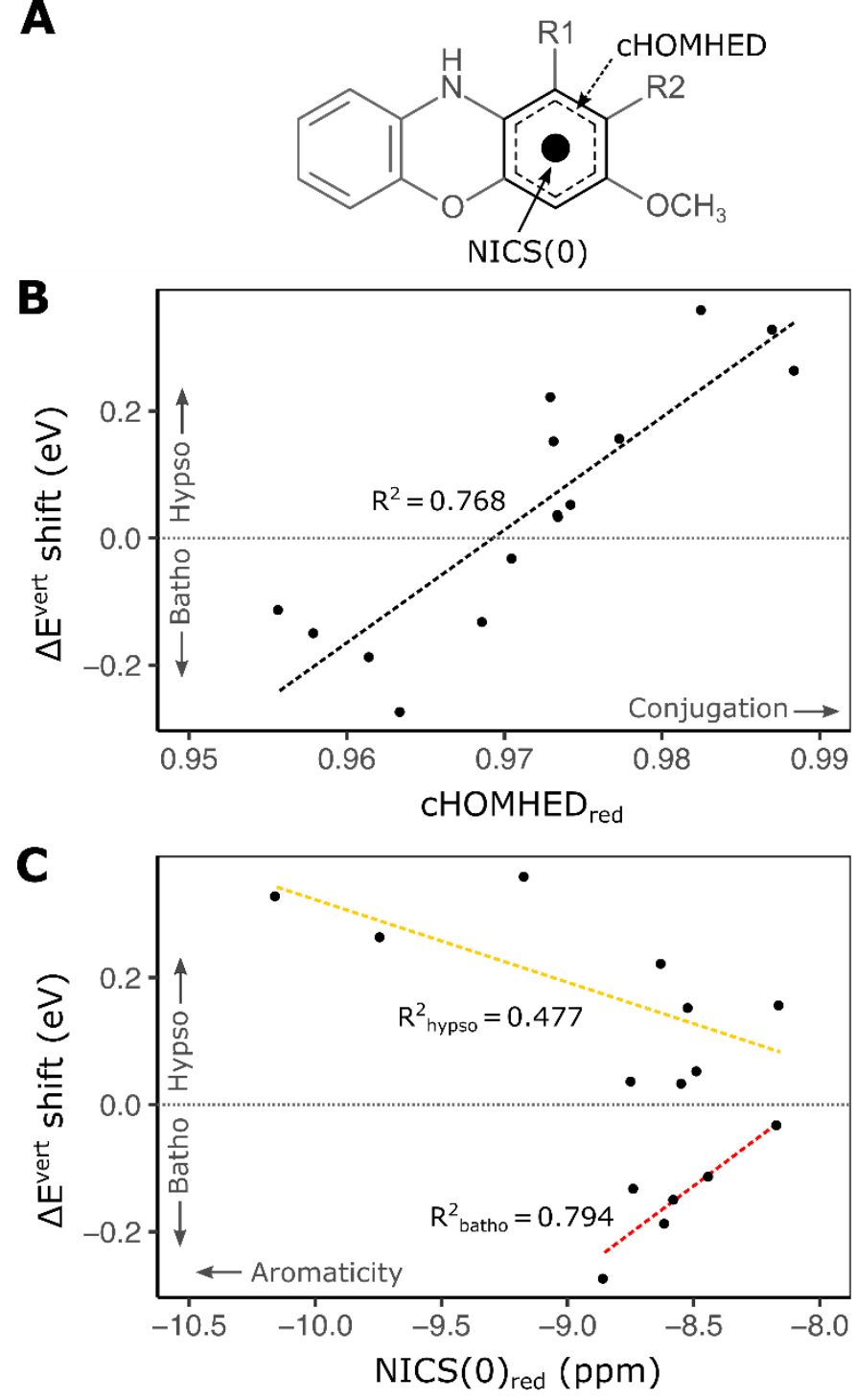

Figure 2 

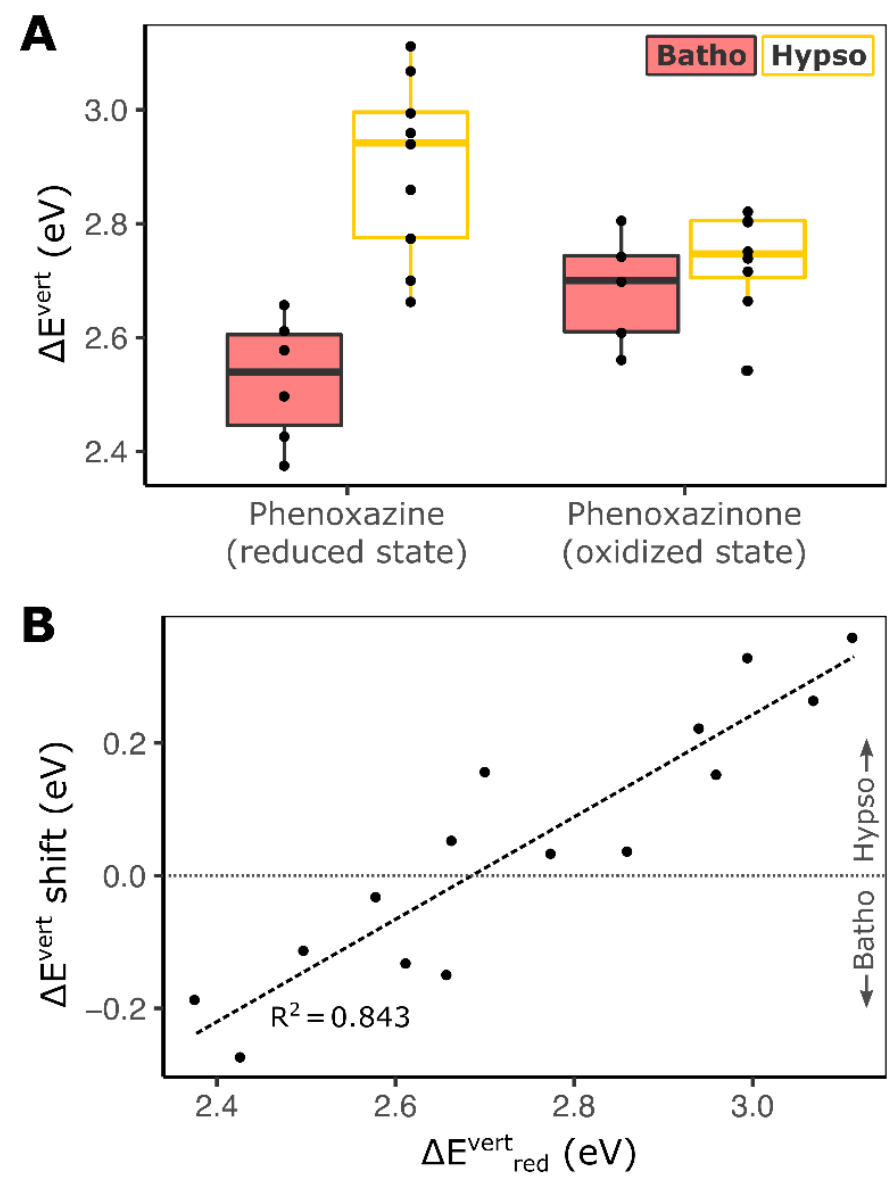

Figure 3 

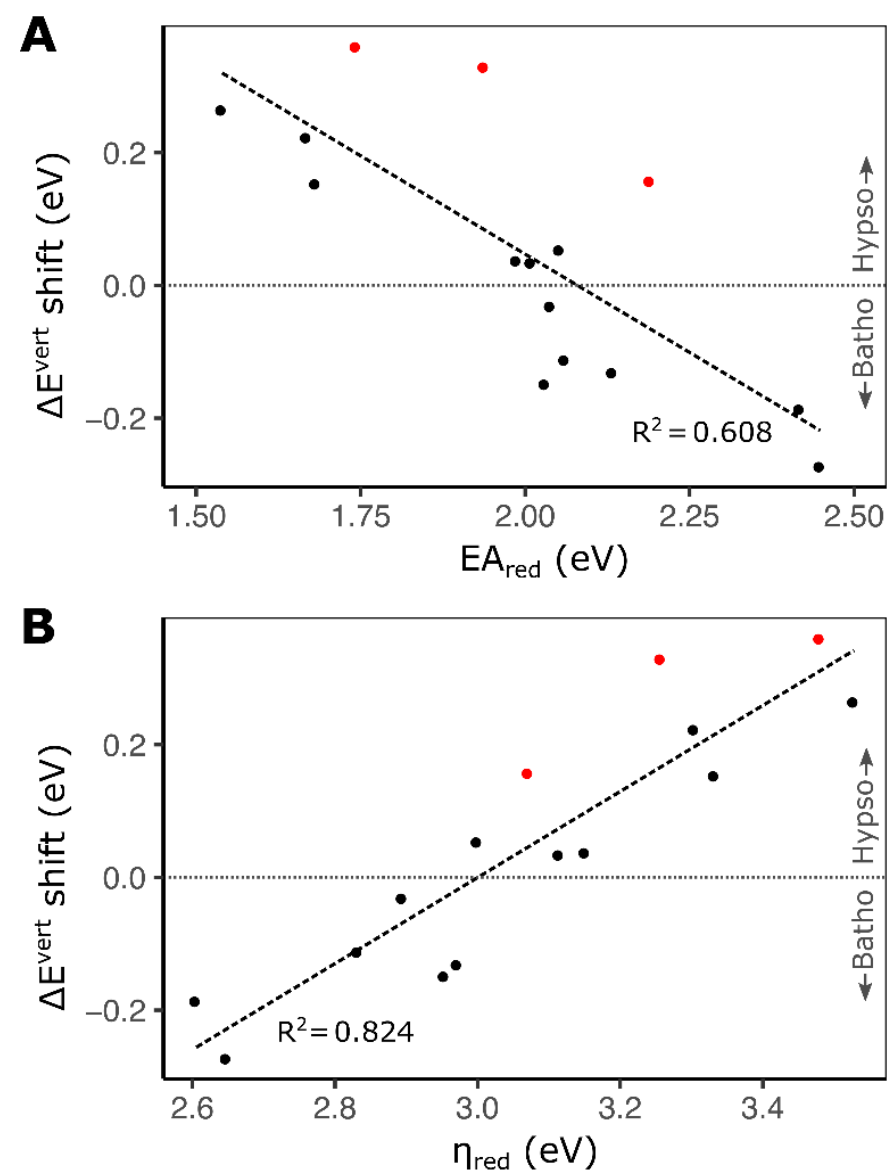

Figure 4 

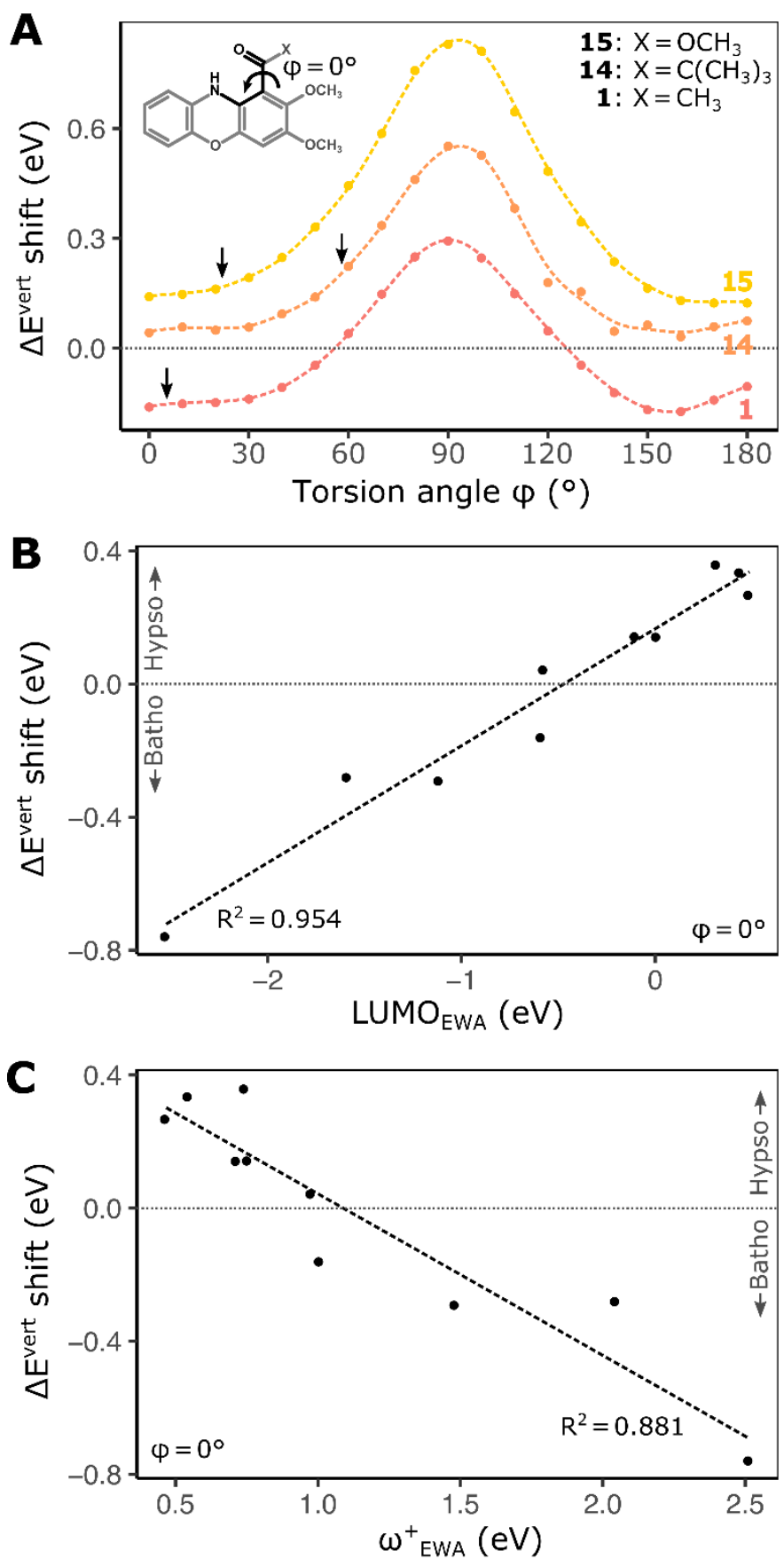

Figure 5 
A

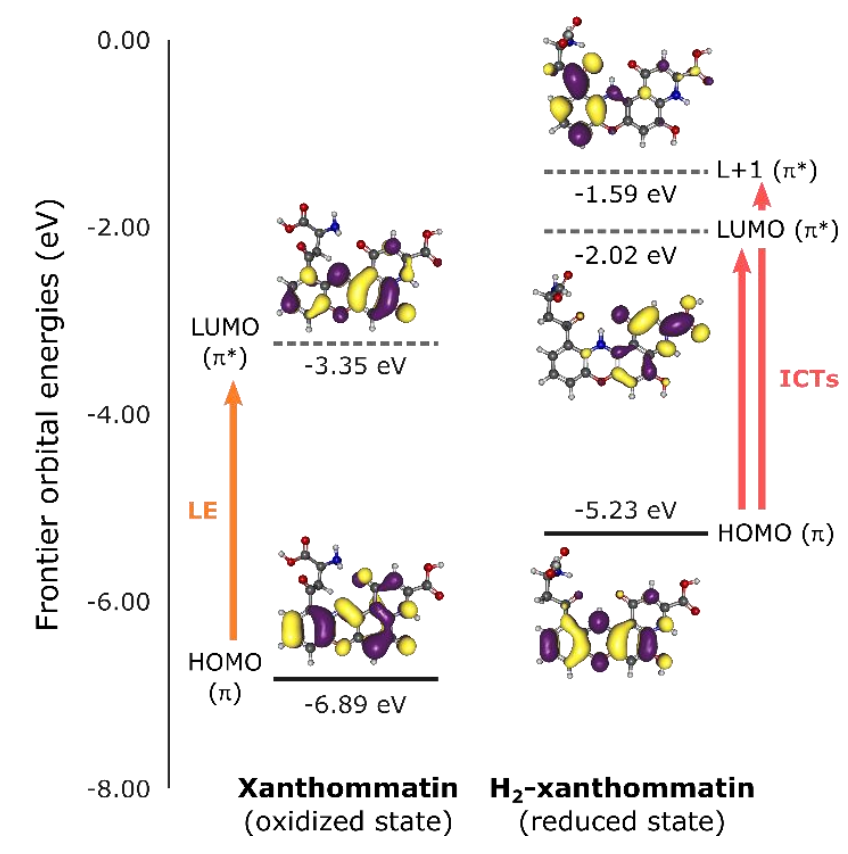

B

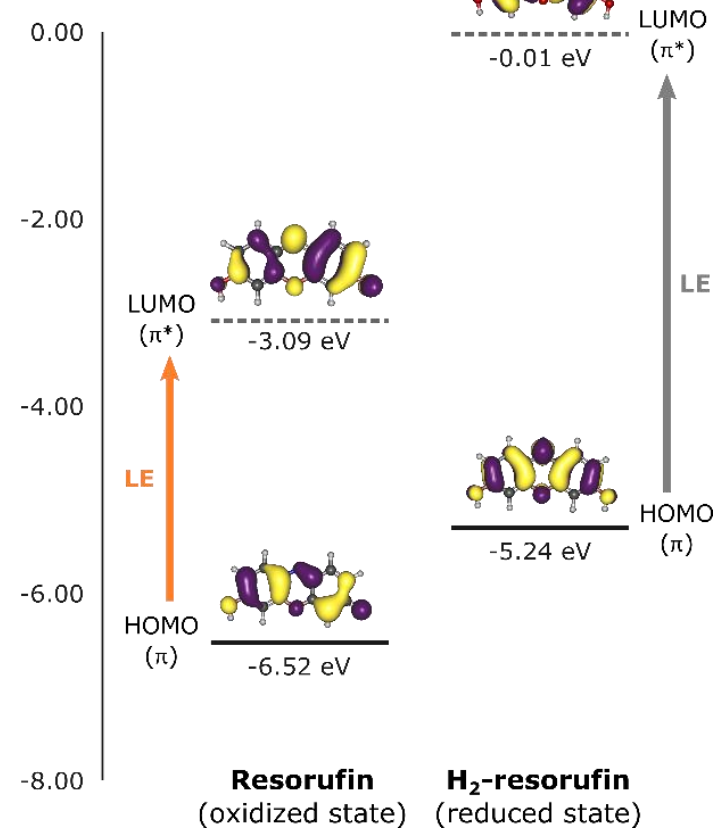

Figure 6 
A

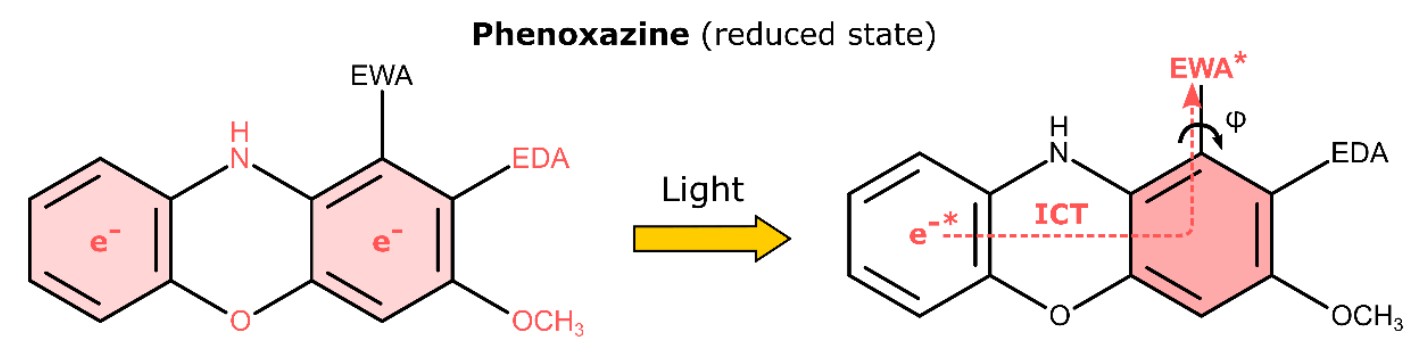

Ground state: HOMO ( $\pi$ )

Excited state: (L)UMO ( $\left.\pi^{*}\right)$

B

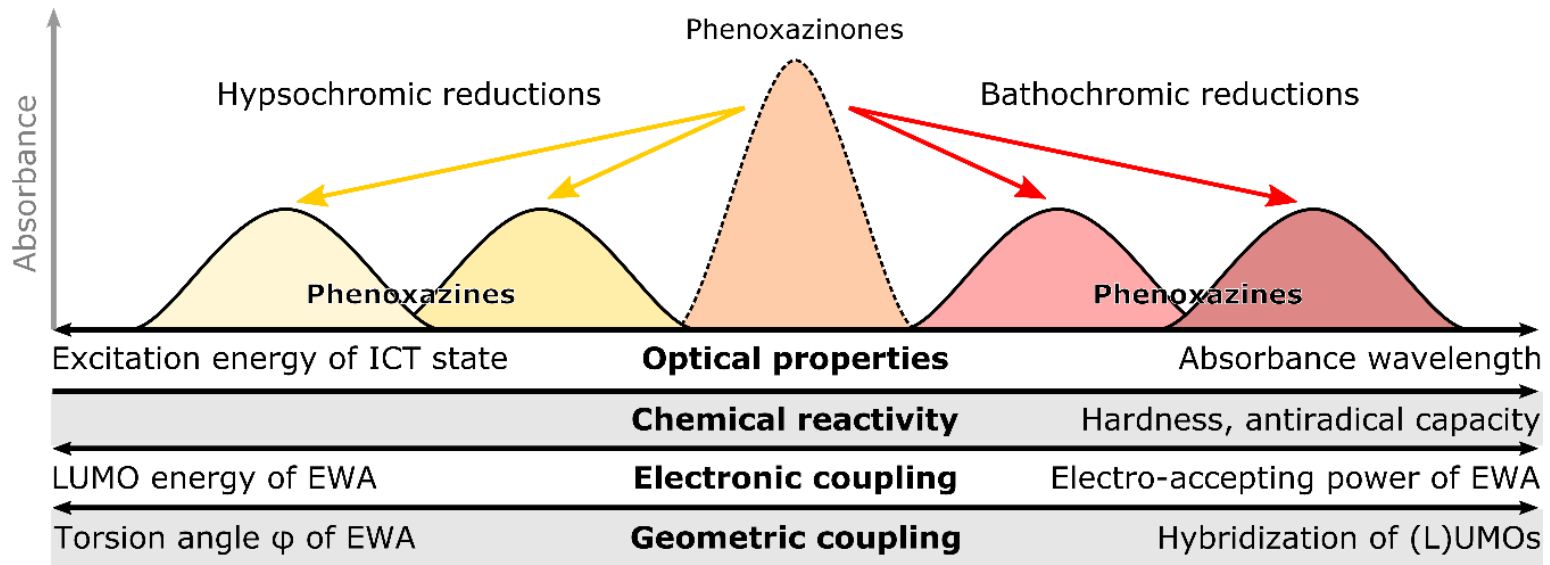

Figure 7 